\title{
O DISCURSO FALACIOSO DO MOVIMENTO ESCOLA SEM PARTIDO
}

\author{
THE SPEAKING SPEECH OF SCHOOL MOVEMENT WITHOUT PARTY \\ EL DISCURSO FALACIO DEL MOVIMIENTO ESCUELA SIN PARTIDO
}

Alexandre Fernando da Silva* xnandosilva@gmail.com

José Heleno Ferreira** zeheleno.ferreira@gmail.com

Carlos Alexandre Vieira***

carlosalexvieira@yahoo.com.br

\begin{abstract}
REVISTA PEDAGÓGICA
Revista do Programa de Pós-graduação em Educação da Unochapecó | ISSN 1984-1566

Universidade Comunitária da Região de Chapecó | Chapecó-SC, Brasil Como referenciar este artigo: SILVA, A. F.; FERREIRA, J. H.; VIEIRA, C. A. O discurso falacioso do movimento Escola Sem Partido. Revista Pedagógica, Chapecó, v. 19, n. 42, p. 49-65, set./dez. DOI: http://dx.doi.org/10.22196/rp.v19i42.4011
\end{abstract}

\begin{abstract}
RESUMO: A democracia brasileira adentrou o século XXI fortalecida pela eleição de um governo de origem operária. Neste período, conquistas de direitos estabelecidas na Constituição de 1988 foram ratificadas. Tal governo foi reconduzido em 2014 através de processo eleitoral democrático e legítimo. Desde então, ataques engendrados pela direita conservadora e lideranças políticas, culminaram na deposição da presidente Dilma Roussef, através de um golpe parlamentar. Rompida a ordem democrática, o ilegítimo presidente Michel Temer foi empossado. Durante este processo, direitos conquistados na constituinte de 1988 sofreram ataques, por meio de reformas propostas pelo governo ilegítimo. $\mathrm{O}$ presente texto busca desmascarar o discurso falacioso do movimento Escola Sem Partido, que ganhou força neste cenário como forma de ataque à educação. Tal discussão perpassa a partir do contexto social de rompimento da ordem democrática e ascensão de forças reacionárias, representantes de interesses neoliberais.
\end{abstract}

Palavras chave: Escola Sem Partido. Golpe Parlamentar. Educação.

ABSTRACT: Brazilian democracy entered the twenty-first century, strengthened by the election of a workers' home government. In this period, rights gains established in the 1988 Constitution were ratified. Such a government was reappointed in 2014 through a democratic and legitimate electoral process. Since then, attacks engendered by the conservative right and political leadership, culminated in the deposition of President Dilma Roussef, through a parliamentary coup. Having broken the democratic order, illegitimate President Michel Temer was sworn in. During this process, rights won in the 1988 constituency were attacked, through reforms proposed by the illegitimate government. This text seeks to unmask the fallacious discourse of the movement Without a Party, which has gained strength in this scenario as a form of attack on education. Such a discussion runs from the social context of disruption of the democratic order and the rise of reactionary forces, representatives of neoliberal interests.

Keywords: No Party School. Parliamentary Coup. Education.

RESUMEN: La democracia brasileña adentró el siglo XXI fortalecida por la elección de un gobierno de origen obrero. En este período, las conquistas de derechos establecidas en la Constitución de 1988 fueron ratificadas. Tal gobierno se reconduce en 2014 a través de un proceso electoral democrático y legítimo. Desde entonces, ataques engendrados por la derecha conservadora y líderes políticos, culminaron en la deposición de la presidente Dilma Roussef, a través de un golpe parlamentario. Rompió el orden democrático, el ilegítimo presidente Michel Temer fue posado. Durante este proceso, derechos conquistados en la constituyente de 1988 sufrieron ataques, por medio de reformas propuestas por el gobierno ilegítimo. El presente texto busca desenmascarar el discurso falaz del movimiento Escuela Sin Partido, que ganó fuerza en este escenario como forma de ataque a la educación. Tal discusión, atravesa desde el contexto social de rompimiento del orden democrático y el ascenso de fuerzas reaccionarias, representantes de intereses neoliberales.

Palabras clave: Escuela sin Partido. Golpe Parlamentario. Educación. 


\begin{abstract}
* Licenciado em Química pela Universidade do Estado de Minas Gerais - Unidade Divinópolis. Doutorando e Mestre em Ciências pela Universidade de Franca - Franca-SP

** Docente na Educação Básica, atuando na área de Ciências Humanas, na Secretaria Municipal de Educação de Divinópolis e no ensino superior, atuando como professor de Filosofia, Política Educacional e Metodologia Científica na Universidade do Estado de Minas Gerais - UEMG - Unidade Divinópolis

*** Coordenador do curso de química e professor das disciplinas: química ambiental e química analítica na Universidade do Estado de Minas Gerais - Unidade de Divinópolis
\end{abstract}

\section{INTRODUÇÃO}

Em 1985, após 21 anos sob uma ditadura civil militar, o Brasil iniciava um novo capítulo em sua história: o período democrático. O processo de redemocratização e conquista de direitos foi lento e gradativo, cujo marco foi a promulgação da Constituição de 1988. A nova Carta Magna, resultado de lutas e reivindicações da sociedade civil organizada contra o regime de opressão, ficou conhecida como "constituição cidadã", pois estabeleceu uma série de direitos ao povo brasileiro (FISCHMANN, 2009). A Carta "[...] introduziu também indiscutível avanço na consolidação legislativa das garantias e direitos fundamentais e na proteção de setores vulneráveis da sociedade brasileira" (PIOVESAN, 2013, p. 84), tornando-se um alicerce da democracia recém-instituída.

Após momentos conturbados, mas de intensa participação popular e sucessivas eleições gerais, a democracia brasileira adentrou o século XXI revigorada. A ascensão ao governo central de um partido de origem operária, por meio do voto popular, marcou a ratificação do regime democrático. Este governo operário, embora fruto de uma coalisão de grupos à esquerda e outros ao centro, não representava os interesses de determinados grupos políticos e econômicos hegemônicos durante grande parte da história brasileira. O resultado deste período foi a consolidação dos direitos estabelecidos na Constituição de 1988 mediante a melhoria de indicadores sociais, fruto de programas de transferência de renda, da estabilização e do crescimento da economia.

A ascensão social de camadas mais pobres da população não interessa às elites tradicionais do país que, ao contrário, veem-na como ameaça à hegemonia da hierarquia social exercida durante a história, sob a força do poder econômico e político centralizado. Dessa forma, em paralelo aos avanços sociais, cresceram também movimentos de determinados grupos que acolheram ideias e discursos conservadores e arcaicos que contariam os avanços sociais das últimas duas décadas e se contrapõem aos ideais progressistas do século XXI. Tais grupos contam com aliados como o poderio do capital, poderio político representado por elites oligárquicas ainda persistentes no cenário nacional e o domínio dos meios de comunicação mais influentes do país. A partir de 2013, com o uso destes recursos, o discurso conservador foi intensificado e, desde então, torna-se crescente. No contraponto, o Brasil vivenciou a reação dos movimentos sociais de maciças manifestações de rua contra o ataque elitista que culminaram no cisalhamento político do país nas eleições presidenciais de 2014. Mesmo diante do acirramento da divisão política e do ataque das elites nacionais, o governo popular foi reconduzido pelo processo eleitoral legítimo e democrático (BRAZ, 2017).

O alto nível de cisão ideológica e a diferença relativamente pequena entre o número de votos alcançados pela 
candidata eleita e pelo candidato derrotado no segundo turno contribuíram para que as eleições presidências de 2014 não garantissem o reconhecimento da vitória do voto popular, persistindo a divisão ideológica e política do país mesmo após o pleito. Por intermédio do poderio da elite conservadora brasileira, a divisão foi exacerbada e, somada à nova formação do Congresso Nacional, um dos mais conservadores da história do país, o processo político culminou com o rompimento da ordem democrática e a deposição da presidente Dilma Rousseff. Tal processo consistiu-se de ato deliberado de lideranças políticas, sobrepondo interesses particulares aos pressupostos das instituições que representam, não sendo o impedimento da presidente um ato originado do funcionamento institucional (SANTOS; SZWAKO, 2016).

Na sucessão da presidente deposta, o ilegítimo presidente Michel Temer foi conduzido à presidência, o que instituiu um governo golpista e representante dos grupos que se alinham às forças conservadoras e reacionárias da sociedade brasileira. O processo de impedimento consistiu de um golpe parlamentar, estabelecido por um acordo entre setores elitistas da sociedade, detentores do capital e dos meios de produção e o congresso conservador. As consequências são ataques aos direitos estabelecidos na Constituição de 1988, por meio da aprovação de reformas que visam ao atendimento das demandas do patronato e do capital, em detrimento da deterioração das relações de trabalho, redução e precarização de serviços públicos e cortes orçamentários em programas sociais (ABRAMIDES, 2017).

Além da ruptura democrática, revelam-se outras consequências como o fortalecimento de movimentos pavimentados em ideias reacionárias, arcaicas e preconceituosas. Tais movimentos surgiram como contraponto às conquistas sociais das últimas décadas e ganham força junto ao discurso conservador crescente no país. Dentre estes, destaca-se o autointitulado movimento Escola Sem Partido (ESP), que tem como pretensão estabelecer parâmetros para a atuação de professores sobre o pretexto de equidade entre correntes ideológicas e políticas. No entanto, o próprio nome do movimento consiste em eufemismo, o verdadeiro caráter é a busca por impor limites à pluralidade de ideias em salas de aula sobre o pretexto que existe um processo continuado de "doutrinação ideológica" dos estudantes brasileiros em favor de determinados grupos políticos (MENEZES, 2017).

A tentativa de supressão da liberdade de atuação docente retrata o momento histórico que o país vive nos últimos anos, que tem levado ao acirramento de ideais políticos antagônicos. Esse cenário tem levado ao surgimento de propostas como a defendida pela ESP, emanadas de percepções equivocadas de sociedade e baseadas em pensamentos odiosos em relação aos ideais progressistas. Em contraponto, estão os educadores brasileiros que, cientes dos sérios prejuízos que tal visão pode trazer à educação 
1 Disponível em: <http://www.escolasempartido.org/quem-somos $>$.

2 Refere-se ao Partido dos Trabalhadores que esteve no Governo Brasileiro durante 13 anos.

3 Conforme entrevista de Miguel Nagib, disponível em: <http://odia.ig.com.br/noticia/ brasil/2015-09-06/escola-sem-partido-quer-fim-da-doutrinacao-de-esquerda. html>.

4 Disponível em: <https://professorescontraoescolasempartido.wordpress.com/ vigiando-os-projetos-de-lei/>. brasileira, defendem a liberdade de atuação docente, a pluralidade de ideias e reestruturação da democracia brasileira. Neste contexto, o presente texto busca discutir o papel da escola e dos educadores no processo de escolarização plural e inclusivo, frente a movimentos como o ESP e aos ataques recentes à democracia brasileira.

\section{O QUE É "ESCOLA SEM PARTIDO"?}

O Movimento Escola Sem Partido foi criado no ano de 2004, idealizado por pessoas sem formação acadêmica mínima para discutir temas relacionados à educação. O ESP se apresenta como "[...] uma iniciativa conjunta de estudantes e pais preocupados com o grau de contaminação político-ideológica das escolas brasileiras, em todos os níveis: do ensino básico ao superior" (NAGIB, [201-], [s. p.])1. Apesar de esta definição designar o termo político-ideológico, o movimento abarca outros pontos que considera ameaças a seus ideais de sociedade, "[...] como práticas sociais libertárias e promotoras de valores como o respeito às diferenças, luta contra o racismo, contra homofobia [...]", contra o sexismo e "demais violências, que ameaçam os direitos humanos" (MENEZES, 2017).

A partir destes pressupostos adota discursos distorcidos da realidade, como para justificar o surgimento do movimento, que seria um contraponto a "[...] uma mentalidade progressista, favorável ao $\mathrm{PT}^{2}$, que auxiliou a manutenção deles no poder" (RESENDE, 2015, [s. p.])3. Mentalidade que, na visão do movimento, foi criada por professores que ao lecionarem adotam posicionamento político partidário e impedem posições contrárias às que defendem no ambiente escolar. Estende essas percepções equivocadas a outras questões como os conteúdos que devem ser abordados em sala de aula, mediante argumentos como "Não se pode obrigar os filhos a aprenderem o que os pais não querem" ou o "governo vem tentando naturalizar o comportamento homossexual" (NAGIB, [201-], [s. p.]).

Em sua fase inicial, o ESP utilizava como estratégia a judicialização das relações escolares de alunos e professores. Posteriormente, passou à influência velada ou mesmo a pressionar o poder legislativo nas esferas municipal, estadual e federal, no intuito de propor projetos de leis que legitimassem os ideais do movimento (MACEDO, 2017). Atualmente, o movimento conta com o site "Professores Contra o Escola Sem Partido" para veiculação de suas ideias que, no topo da página, expõe seu principal posicionamento com o termo "educação sem doutrinação". No endereço eletrônico, é possível encontrar espaço para relatar supostos casos de "doutrinação político-ideológica em sala de aula", ter acesso a instrumentos de denúncia e materiais de divulgação do movimento. 
Como resultado do crescente sentimento conservador de setores da sociedade brasileira e pela influência do movimento ESP, vários projetos de leis tramitam nas casas legislativas do país. Segundo levantamento disponibilizado no site "Professores Contra o Escola Sem Partido", há, na esfera federal, oito projetos com base no modelo de anteprojeto disponibilizado no site do Escola Sem Partido (NAGIB, [201-]). Os projetos buscam alterar documentos que regem o planejamento da educação nacional, como a Lei de Diretrizes e Bases da Educação Nacional (LDBEN), Parâmetros Curriculares Nacionais ( $\mathrm{PCN}^{\prime} \mathrm{s}$ ), Base Nacional Comum Curricular (BNCC) e Plano Nacional de Educação (ALGEBAILE, 2017). Todos os textos apresentam conteúdos semelhantes e impõem a limitação da atividade docente pela censura de temas considerados inadequados sob a perspectiva do ESP. Alguns apresentam trechos esdrúxulos como o $\mathrm{PL} \mathrm{n}^{0}$ 1.859/2015 que visa a acrescentar à LDB os seguintes dizeres:

Parágrafo único: A educação não desenvolverá políticas de ensino, nem adotará currículo escolar, disciplinas obrigatórias, ou mesmo de forma complementar ou facultativa, que tendam a aplicar a ideologia de gênero, o termo 'gênero' ou 'orientação sexual'. (BRASIL, 2015, p. 1).

Ainda, segundo levantamento do blog, tramitam nas casas legislativas estaduais e municipais ao menos outros oito projetos espelhados no ESP. Tais projetos ainda tramitam mesmo após o Ministério Público Federal (MPF) posicionar-se pela inconstitucionalidade de PL aprovado no estado de Alagoas sob o eufemismo "Escola Livre", mas que tem inspiração clara no movimento ESP. Segundo as Ações Diretas de Inconstitucionalidade das Leis $\mathrm{n}^{0}$ 5.537/AL e ${ }^{0}$ 5.580/AL (Lei "Escola Livre"), declaradas pela Procuradoria Geral da União (PGR):

Há equívocos conceituais graves na norma, como o de considerar que o alunado seria composto de indivíduos prontos a absorver de forma total, passiva e acrítica quaisquer concepções ideológicas, religiosas, éticas e de outra natureza que os professores desejassem. Despreza a capacidade reflexiva dos alunos, como se eles fossem apenas sujeitos passivos do processo de aprendizagem, e a interação de pais e responsáveis, como se não influenciassem a formação de consciência dos estudantes. (MPF, 2016, p. 22).

O texto cita ainda:

Desconsidera que, em termos pedagógicos, a rotina em sala de aula é essencialmente dialógica, e há espaço para que os alunos suscitem dúvidas e inquietudes e promovam debates, 
muitas vezes até no nível pessoal ou envolvendo temáticas como religião e política, para as quais não há respostas necessariamente fechadas ou definitivas. Tomar o estudante como tábula rasa a ser preenchida unilateralmente com o conteúdo exposto pelo docente é rejeitar a dinâmica própria do processo de aprendizagem. (MPF, 2016, p. 23).

O movimento demonstrou sua força e capacidade de articulação durante o processo de elaboração dos planos decenais da educação, entre os anos 2014 e 2016, seja na esfera nacional, seja nas esferas estaduais e municipais. Como resultado da atuação dos grupos ligados ao ESP, em vários entes federativos os planos decenais de educação suprimiram artigos e capítulos que tratavam da diversidade étnico-racial, religiosa e, principalmente, de gênero. Não há dúvida de que saímos, enquanto nação, mais pobres deste processo em que a diversidade foi negada em nome de uma suposta ordem natural à qual devem se adequar todos e todas.

A pretensa visão do ESP que "prega" uma educação neutra e apolítica é desmascarada ao ler os textos do movimento e de projetos de lei que são fundamentados em seus pressupostos, cujos dizeres estão fortemente atrelados a discursos da direita conservadora. A própria instituição de um movimento desta natureza é um ato político, assim como todo ato humano. A proposição da intitulada "educação sem doutrinação" é, por essência, um posicionamento contrário à discussão de ideias e uma incapacidade de determinados setores da sociedade brasileira em lidar com a diversidade. Essa incapacidade transpõe-se para a intolerância a correntes políticas contrárias àqueles que o movimento tem por base. No entanto, a pluralidade política é fruto da ação humana e a tolerância uma condição para o convívio social na coletividade e respeito às individualidades. Conforme Arendt, "[...] a pluralidade é a condição da ação humana pelo fato de sermos todos os mesmos, isto é, humanos, sem que ninguém seja exatamente igual a qualquer pessoa que tenha existido, exista ou venha a existir" (ARENDT, 2007, p. 15).

A educação não é diferente, também é um ato político. O educador está em posição de diálogo, assim como os estudantes, e discussões acerca de temas diversos e, por vezes, adversos a determinados grupos da sociedade fazem-se necessárias à construção do saber e à formação integral do indivíduo.

\section{A ESCOLA, A EDUCAÇÃO E SEUS PAPÉIS NA SOCIEDADE}

A instituição escolar como a conhecemos atualmente tem origem no século XVII, mas a educação remonta ao surgimento das comunidades humanas. Educar consistia na vivência, no contato com a comunidade e por 
conhecimentos transmitidos naturalmente através da tradição oral. A escola como instituição ganha força apenas com a Revolução Industrial, com a demanda por pessoas minimamente capacitadas quanto à leitura, escrita e aritmética. Diante da crescente classe trabalhadora urbanizada surge a necessidade da escolarização para socializar e incutir no indivíduo padrões de disciplina diante da estratificação social (COIMBRA, 1989). Neste sentido, a escola adentra o século XX com claras funções diante da sociedade moderna: transmitir conhecimentos para formação da classe trabalhadora, justificar hierarquias sociais e interiorizar em cada indivíduo a posição social em acordo com a origem (DUBET; DURU-BELLAT; VÉRÉTOUT, 2012).

A escola como estrutura física não passa de apenas mais um edifício na paisagem urbana. $\mathrm{O}$ que constitui a escola como instituição são estudantes e professores e a relação destes com o conhecimento sistematizado e com a comunidade. As aulas, os temas debatidos, os conteúdos ensinados, nada disso é retido dentre os muros da escola, transcendem as barreiras físicas e chegam à sociedade em variados ambientes pela interação social de seus agentes, especialmente os estudantes. A escola é espaço de diversidade, recebe cotidianamente, no mesmo ambiente, indivíduos de várias origens (SILVA; FERREIRA, 2014). Assim, pode-se entender a educação em sentido amplo, como um processo coletivo de formação intelectual, construção de saberes e cidadania, pela troca de informações, debates de ideias e convívio social.

As transformações socioculturais, políticas e econômicas do final do século XX e início deste século, como não poderia deixar de ser, afetam também a instituição escolar. O modelo de educação padronizador, em que estudantes recebem os conhecimentos de forma acumulativa e são formados na escola, como produtos são fabricados em uma linha de produção, não cabe na discussão sobre o papel da escola na pós-modernidade. A escola deve ser percebida como transformadora, instrumento para a quebra de paradigmas sociais e essencial na construção de sociedades equânimes. $\mathrm{O}$ exercício pleno deste papel social somente ocorre pela diversidade de pensamento, discussões de ideias, contraponto de opiniões. Dentre os papéis fundamentais da escola está o de possibilitar ao educando perceber o mundo para além da sua realidade cotidiana, buscando, dessa forma, contribuir com um processo de formação que alie o acesso ao conhecimento sistematizado à capacidade de percepção do mundo para além da realidade imediatamente dada. Assim, a escola, na constituição de espaço social é oportunidade para a construção da cidadania, através de currículos e práticas pedagógicas que percebam os alunos como sujeitos do processo ensino-aprendizagem. E, por meio deste caminho, ao romper com a uniformidade da escola e estabelecer um ensino para emancipação do indivíduo pela crítica e reflexão, contribui para a construção de uma nação também emancipada, conforme afirmam Frigotto e Chiavatta (2003, p. 93-130): 
Neste sentido, a educação é tanto um direito social básico e universal quanto vital para romper com a histórica dependência científica, tecnológica e cultural do país, e fundamental para a construção de uma nação autônoma, soberana e solidária na relação consigo mesma e com outras nações. A educação é, portanto, ao mesmo tempo determinada e determinante da construção do desenvolvimento social de uma nação soberana. Além de ser crucial para uma formação integral humanística e científica de sujeitos autônomos, críticos, criativos e protagonistas da cidadania ativa, é decisiva, também, para romper com a condição histórica de subalternidade e de resistir a uma completa dependência científica, tecnológica e cultural.

O educador é o catalisador desta escola pensada para o educando, fazendo da atividade docente a conexão entre o aluno, o conhecimento formal, as relações humanas e sociais. Somente por intermédio de uma educação crítica e transformadora é possível estabelecer a quebra de padrões sociais estabelecidos previamente por elites econômicas e culturais, e possibilitar mudanças na estrutura social. Dessa forma, pensar no papel da escola como transformadora sem considerar que a docência seja ativa, é desqualificar a figura do educador como sujeito de sua própria ação e submetê-lo à condição de "fantoche" de vontades de determinados grupos sociais. $\mathrm{O}$ ato de educar é essencialmente um exercício político, submetido às percepções de mundo e vivências do educador. Propor uma educação em que o professor seja neutro é criar uma realidade paralela, que tem como pano de fundo o objetivo de subjugar ou intimidar a atividade docente e impor uma pedagogia distorcida. Não há neutralidade nesta proposta, como não há na atividade docente, como já anunciava o educador brasileiro Paulo Freire.

[...] não há nem jamais houve prática educativa em espaço-tempo nenhum de tal maneira neutra, comprometida apenas com ideias preponderantemente abstratas e intocáveis. Insistir nisso e convencer ou tentar convencer os incautos que essa é a verdade é uma prática política indiscutível com que se pretende amaciar a possível rebeldia dos injustiçados. Tão política quanto a outra, a que não se esconde, pelo contrário, proclama, sua politicidade. (FREIRE, 1992, p. 78).

A responsabilização da escola como única influenciadora na formação de pensamento dos estudantes é equivocada. A escola não é o único espaço para a educação, assim como o educador não é responsável solitário por esta tarefa. A família é parte fundamental deste processo. Não 
cabe delimitar onde inicia a responsabilidade familiar e escolar na educação, mas certamente há uma distinção entre educação formal (ou escolarização) e a educação atribuída à família. Nos processos de escolarização, são transmitidos saberes científicos e sistematizados em conteúdos organizados em currículos. A educação informal ocorre no ambiente familiar, bem como em outros ambientes em que o indivíduo aprende hábitos diários, costumes, religiosidade e cultura (BIESDORF, 2011). Portanto, o estudante é educado pela interação da aprendizagem nestes ambientes, constrói suas perspectivas e ideias a partir destas vivências, não sendo mero receptor das informações transmitidas durante a atividade docente.

A abordagem inicial do movimento é sedutora, sob uma perspectiva de escola que assuma seus papéis de formação sem influências de qualquer que seja a corrente ideológica ou política. É razoável afirmar que é a vontade dos educadores criar uma escola sem interferências de ordem política, religiosa ou moral; com profissionais bem remunerados e respeitados, sem medo de "policiamento" ideológico de pais e estudantes. Vale estender esta vontade a outros setores da sociedade, como também se faz necessário um Estado laico; um judiciário que não se submeta ao poderio econômico e político; uma mídia com apreço aos fatos, sem partidarismo, ou que ao menos expresse sua posição ideológica sem alarde de uma pseudoneutralidade; partidos políticos que trabalhem por interesses coletivos, pela soberania nacional, pelo fortalecimento da democracia e que estejam submetidos à vontade popular também fora de períodos eleitorais; enfim, uma sociedade em que o interesse comum prevaleça sobre ideais espúrios (HEUSER, 2017). Mas estes não são os propósitos finais e, sim, a manutenção do status quo social, perpetuando preconceitos e desigualdades.

O propósito de movimentos como o Escola Sem Partido é desestruturar a função da escola na sociedade e colocá-la a serviço de seus próprios interesses. A formação de pessoas limitadas, intolerantes com as diferenças e com uma visão de mundo que se adéqua apenas aos objetivos de determinados grupos conservadores tem como objetivo negar o questionamento e o posicionamento crítico diante da realidade. Mas, vale ressaltar, é inerente à atividade humana a não neutralidade, como assim é também na práxis educacional. A existência de educadores que expressam suas opiniões favoráveis a ideias progressistas ou conservadoras é parte do processo, isso é parte do exercício da docência, desde que esteja compreendido nos limites éticos e legais. Nesta realidade, promover o pensamento livre por uma educação reflexiva e crítica torna-se fundamental na construção de cidadãos que respeitem opiniões, reflitam e construam suas próprias convicções. 


\section{A TENTATIVA DE AMORDAÇAR OS PROFESSORES}

$\mathrm{Na}$ análise das propostas do ESP e o contexto atual da educação brasileira, é preciso estabelecer uma conexão com a realidade. O Brasil é um país de intensa desigualdade social originada de séculos de relações sociais assimétricas, que excluíram (e ainda excluem) grupos sociais de acordo com cor da pele, origem geográfica, gênero, orientação sexual e poder econômico, ou qualquer condição que desafie a manutenção da estrutura social. A educação, como reflexo da sociedade, é permeada por estas relações segregadas. Essa condição manteve-se perene durante a história brasileira por políticas públicas inadequadas, baixo investimento em estruturas, desvalorização da carreira docente, acesso restrito ao sistema educacional e metodologias de ensino padronizadas que desconsideravam a diversidade social.

Resultados deste processo, entre outros, são os baixos índices educacionais do país quando comparado a outras nações. No quesito qualidade de ensino, o sistema educacional brasileiro ocupa apenas a $131^{\text {a }}$ posição, segundo o relatório Global Information Technology, divulgado em 2016 pelo Fórum Econômico (UNESCO, 2016). No Programa Internacional de Avaliação de Alunos (PISA - sigla de Program for International Student Assessment), o Brasil ocupa as discretas posições em $59^{\mathrm{a}}$ em ciências, $59^{\mathrm{a}} \mathrm{em}$ leitura e na $66^{\mathrm{a}}$ em matemática. A avaliação do PISA contempla 70 países e foi divulgada em 2016 pela Organização para Cooperação e Desenvolvimento Econômico (OCDE, 2016).

A desvalorização da educação como instrumento de igualdade social e o acesso restrito a este serviço com boa qualidade atende aos interesses intrínsecos de determinados setores da sociedade. Os cidadãos de uma sociedade com baixa escolarização não tomam consciência de seus direitos e tampouco podem exigi-los. Assim, as elites econômicas e culturais mantêm as massas sob o "cabresto" da ignorância. No entanto, a educação é importante para o desenvolvimento econômico de uma nação. Os meios de produção obtêm do conhecimento científico o aprimoramento de sistemas e produtos de consumo. Aqui, destaca-se um paradoxo: apesar de importante para o sistema de produção, o conhecimento não pode ser acessado por todos; e alguns têm acesso somente ao mínimo necessário para o domínio da atividade produtiva. Excedê-lo significaria expor a ordem social a riscos de rupturas. Saviani (1994, p. 161) descreve esta concepção:

A sociedade capitalista é baseada na propriedade privada dos meios de produção. Se os meios de produção são propriedade privada, isto significa que são exclusivos da classe dominante, da burguesia, dos capitalistas. Se o 
saber é força produtiva deve ser propriedade privada da burguesia. Na Medida em que o saber se generaliza e é apropriado por todos, então os trabalhadores passam a ser proprietários de meios de produção. Mas é da essência da sociedade capitalista que o trabalhador só detenha a força de trabalho. Aí está a contradição que se insere na essência do capitalismo: o trabalhador não pode ter meio de produção, não pode deter o saber, mas, sem o saber, ele também não pode produzir, porque para transformar a matéria precisa dominar algum tipo de saber. Sim, é preciso, mas "em doses homeopáticas", apenas aquele mínimo para poder operar a produção. E difícil fixar limite, daí por que a escola entra nesse processo contraditório: ela é reivindicada pelas massas trabalhadoras, mas as camadas dominantes relutam em expandi-la.

Nessa perspectiva, as elites detentoras dos meios de produção, lançam ataques à educação brasileira, no intuito de manter sob seu controle o que deve ser ensinado, além de como e quando ensinar. Para atender a esses interesses, há uma persistência em erros cometidos durante a história brasileira. Os problemas históricos da educação nacional persistirão, “[...] enquanto as forças dominantes se negarem a pôr em prática as medidas que a experiência já chancelou como sendo as apropriadas para as questões que estamos enfrentando" (SAVIANI, 2004, p. 54).

As classes dominantes usam de muitas formas para atacar a educação, o currículo consiste em uma delas. Recentemente, atendendo a "ode" conservadora que pulsa no país nos últimos anos, o governo (ilegítimo) de Michel Temer, lançou mão do mecanismo de medida provisória (MP) para impor uma reforma no Ensino Médio. A medida provisória é um mecanismo que tem prerrogativas para ser utilizada: urgência e relevância (BRASIL, 1988). É consenso entre educadores que o Ensino Médio necessita de reformulação; contudo, para isso ocorrer, demanda discussões entre educadores, pais e estudantes. O meio legítimo de fazê-lo é através de projeto de lei submetido ao Congresso Nacional para amplas discussões de setores da sociedade. No entanto, o instituto da MP, utilizado fora de suas prerrogativas, consiste em um instrumento de imposição arbitrária de políticas públicas, sob a ação de um governo ilegítimo e transitório.

A MP da Reforma do Ensino Médio, que posteriormente foi aprovada no Congresso Nacional, na forma de Lei $\mathrm{n}^{0} 13.415$, de 16 de fevereiro de 2017, impõe alterações à Lei de Diretrizes e Bases da Educação Nacional, publicada em 1996. Tais alterações tratam da flexibilização do currículo, estabelecendo uma base mínima obrigatória de conteúdos como Matemática e Língua Portuguesa. Disciplinas como Sociologia e Filosofia, fundamentais ao reconhecimento da autoconsciência, tornam-se opcionais. Mas 
a mudança relevante e que vai diretamente ao encontro dos interesses neoliberais está na oportunidade de "escolha" do estudante entre as áreas do conhecimento e a formação profissional. Esse ponto da reforma claramente acentuará a dicotomia entre educação ampla, acessível aos jovens oriundos das classes média e alta, e uma educação limitada à preparação para determinado setor produtivo, acessada por jovens de menor poder econômico. Outro ponto desta reforma é o fomento da escola em período integral, que claramente contrapõe o primeiro item. Educação integral não se restringe ao período de permanência na escola e, sim, à apropriação de conceitos amplos, que preparam o indivíduo para cidadania. A oportunidade de escolha descontrói a integralidade da educação, optar entre uma educação integral ou profissional limita as áreas de conhecimento acessadas e consequentemente, limita a formação.

A colonização do currículo escolar é apenas um caminho encontrado pelo neoliberalismo para impor seus objetivos e descaracterizar o papel do educador frente à formação do educando. Retirar dos educadores a prerrogativa de definições curriculares e responsabilizar os estudantes por estas escolhas apenas descaracteriza um dos papéis fundamentais da escola: orientar e construir um currículo que seja significativo e vinculado à realidade do estudante. Segundo afirma Young (2007, p. 1297):

[...] se as escolas devem cumprir um papel importante em promover a igualdade social, elas precisam considerar seriamente a base de conhecimento do currículo, mesmo quando isso parecer ir contra as demandas dos alunos (e às vezes de seus pais). As escolas devem perguntar: "Este currículo é poderoso?”. Para crianças de lares desfavorecidos, a participação ativa na escola pode ser a única oportunidade de adquirirem conhecimento poderoso e serem capazes de caminhar, ao menos intelectualmente, para além de suas circunstâncias locais e particulares. Não há nenhuma utilidade para os alunos em se construir um currículo em torno da sua experiência, para que este currículo possa ser validado e, como resultado, deixá-los sempre na mesma condição.

Diante deste contexto de desafios, os educadores possuem na educação dialógica e crítica, o antídoto ao imperialismo neoliberal que avança sobre os diretos sociais conquistados na constituição de 1988.

É neste sentido, entre outros, que a pedagogia radical jamais pode fazer nenhuma concessão às artimanhas do "pragmatismo" neoliberal que reduz a prática educativa ao treinamento técnico-científico dos educandos. Ao treinamento e não à formação. A necessária formação técnico-científica dos educandos por que 
se bate a pedagogia crítica não tem nada que ver com a estreiteza tecnicista e cientificista que caracteriza o mero treinamento. É por isso que o educador progressista, capaz e sério, não apenas deve ensinar muito bem sua disciplina, mas desafiar o educando a pensar criticamente a realidade social, política e histórica em que é uma presença. (FREIRE, 2000, p. 43-44, grifos do autor).

A proposta do movimento Escola Sem Partido nada mais é do que mais um ataque ao exercício da livre docência e à liberdade de expressão. Essa visão distorcida e retrógrada da atividade docente visa ainda a fomentar uma sociedade de vigilância ostensiva, contra a diversidade e pluralismo cultural, religioso, sexual e político. Em palavras mais diretas, consiste em uma tentativa de impor mordaça em educadores que buscam a formação integral dos jovens, estabelecer um estado de exceção tendo como arena a sala de aula.

Tais movimentos surgem em resposta à crise atual do sistema capitalista, cuja classe dominante não conseguiu impor-se racionalmente e necessita do uso de mecanismos coercitivos, como a ESP e a ações verticais como a recente reforma do Ensino Médio. Somado a este contexto, a formação histórica da sociedade brasileira, em que há a persistência de grupos hegemônicos, que resistem à inclusão da população em discussões e decisões políticas. Tais grupos, diante da crise contemporânea do capitalismo, veem-se acuados. Como resposta, mobilizam setores da direita conservadora através de discursos odiosos, e para propagá-los fazem uso de suas "armas" tradicionais - meios de comunicação, poder político e econômico -, estendo as manifestações às redes sociais e às ruas. A aprovação de uma lei que amordaça professores significará substituir a democracia como forma de regime soberano e popular, pela vontade de pequenos grupos detentores do capital, meios de produção e poder político (SAVIANI, 2017). Nesse contexto, defender que educadores tenham liberdade de expressão não significa defender que a escola seja palco de disputas políticas, mas que seja, palco de discussões de ideias, sem opressão, disseminação de conhecimentos e que a educação, como direito, seja acessada por toda a população, independentemente de classe e origem.

\section{CONSIDERAÇÕES FINAIS}

O movimento Escola Sem Partido, por meio de um discurso falacioso em que defende uma escola sem influências de grupos políticos, defende, de fato, interesses políticos e a manutenção da ordem social excludente que impera no Brasil desde a colonização. E, na defesa desses interesses, levanta como bandeira a criminalização dos movimentos sociais e o ataque às iniciativas que defendem o respeito, o reconhecimento e a valorização da diversidade. 
Nada mais ideológico, portanto, do que uma "escola sem partido”. Ao contrário, há que se tomar partido, ou seja, há que se posicionar. Cabe ao educador posicionar-se diante do mundo e contribuir para que os educandos possam também construir, através do diálogo, seus próprios posicionamentos. Sem dúvida, os teóricos do ESP, quando defendem a neutralidade e se afirmam não partidários, demonstram claramente suas intenções reacionárias em relação aos avanços e às conquistas da sociedade brasileira nos últimos anos.

É por meio da escuta de todas as opiniões, com uma pedagogia dialética que estimule leituras, visitas a museus, cinemas e exposições, e realização de experiências diversas que o educando terá condições de construir seu próprio repertório. E o professor - por extensão, a escola - deve orientar este processo, sem, obviamente, catequizar o outro.

Novamente, afirma-se a necessidade de que educadores e educadoras tomem o partido do diálogo, do debate crítico, da luta pela emancipação humana e pelo fim dos privilégios que se contrapõem a uma cultura de respeito aos direitos humanos.

\section{REFERÊNCIAS}

ABRAMIDES, Maria Beatriz Costa. Lutas sociais e desafios da classe trabalhadora: reafirmar o projeto profissional do serviço social brasileiro. Serv. Soc. Soc., São Paulo, n. 129, p. 366-386, maio/ago. 2017.

ALGEBAILE, Eveline. Escola sem Partido: o que é, como age, para que serve. In: FRIGOTTO, Gaudêncio. Escola "sem Partido": Esfinge que ameaça a educação e a sociedade brasileira. Rio de Janeiro: UERJ; LPP, 2017. p. 50-63.

ARENDT, Hannah. A Condição Humana. 10. ed. São Paulo: Editora Forense-Universitária, 2007.

BIESDORF, Rosane Kloh. O papel da educação formal e informal: educação na escola e na sociedade. Intinerarius Reflectionis, v. 1, n. 10, p. 1-13, 2011.

BRASIL. Constituição (1988). Constituição da República Federativa do Brasil. Brasília, DF: Senado, 1988.

BRASIL. Congresso Nacional. Projeto de Lei 1859/2015. Acrescenta Parágrafo único ao artigo $3^{\circ}$ da Lei 9.394/96 (Lei de Diretrizes e Bases da Educação). Disponível em: <http://www.camara.gov.br/proposicoesWeb/prop_mos trarintegra? codteor $=1346799 \&$ filename $=P L+1859 / 2015>$. Acesso em: 27 set. 2017.

BRASIL. Lei $\mathrm{n}^{\mathbf{0}} \mathbf{1 3 . 4 1 5}$, de 16 de fevereiro de 2017. Altera as Leis $\mathrm{n}^{\text {os }}$ 9.394, de 20 de dezembro de 1996, que 
estabelece as diretrizes e bases da educação nacional, e 11.494, de 20 de junho 2007, que regulamenta o Fundo de Manutenção e Desenvolvimento da Educação Básica e de Valorização dos Profissionais da Educação, a Consolidação das Leis do Trabalho - CLT, aprovada pelo Decreto-Lei $\mathrm{n}^{0} 5.452$, de $1^{\circ}$ de maio de 1943 , e o Decreto-Lei $\mathrm{n}^{0} 236$, de 28 de fevereiro de 1967; revoga a Lei $\mathrm{n}^{0} 11.161$, de 5 de agosto de 2005; e institui a Política de Fomento à Implementação de Escolas de Ensino Médio em Tempo Integral. 2017. Disponível em: <http://www2.camara.leg.br/legin/ fed/lei/2017/lei-13415-16-fevereiro-2017-784336-publicacaooriginal-152003-pl.html>. Acesso em: 10 mar. 2017.

BRAZ, Marcelo. O golpe nas ilusões democráticas e a ascensão do conservadorismo reacionário. Serv. Soc. Soc., São Paulo, n. 128, p. 85-103, jan./abr. 2017.

COIMBRA, Cecília Maria B. As funções da instituição escolar: análise e reflexões. Psicol. cienc. prof. [online], 1989, v. 9, n. 3, p. 14-16, 1989.

DUBET, François; DURU-BELLAT; Marie; VÉRÉTOUT, Antoine. As desigualdades escolares antes e depois da escola: organização escolar e influência dos diplomas. Sociologias, Porto Alegre, ano 14, n. 29, p. 22-70, jan./abr. 2012.

FISCHMANN, Roseli. Constituição brasileira, direitos humanos e educação. Rev. Bras. Educ. [online], v. 14, n. 40, p. 156-167, 2009.

FREIRE, Paulo. Pedagogia da esperança: um reencontro com a pedagogia do oprimido. Rio de Janeiro: Paz e Terra, 1992.

Pedagogia da Indignação: cartas pedagógicas e outros escritos. São Paulo: Unesp, 2000,

FRIGOTTO, Gaudêncio; CIAVATTA, M. Educação básica no Brasil na década de 1990, subordinação ativa e consentida à lógica do mercado. Educação e Sociedade, Campinas, v. 24, n. 82, p. 93-130, abr. 2003.

HEUSER, Ester Maria Dreher. Em tempos de escola sem partido, perguntemo-nos: qual a função da educação em uma sociedade? O que cabe à escola e ao professor? ETD - Educação Temática Digital Campinas, São Paulo, v. 19, n. esp., p. 206-216, jan./mar. 2017.

MACEDO, Elizabeth. As demandas conservadoras do movimento escola sem partido e a base nacional curricular comum. Educ. Soc., Campinas, v. 38, n. 139, p. 507-524, abr./jun. 2017.

MENEZES, Leopoldina Cachoeira. "Escola sem Partido": uma ameaça à formação em Gênero e Diversidade. 
2017. Disponível em: <http://www.apub.org.br/wp-content/uploads/2016/o8/texto-para-o-proifes-Leopoldina. pdf $>$. Acesso em: 26 set. 2017.

MINISTÉRIO PÚBLICO FEDERAL. Procuradoria Geral da República. Ações diretas de inconstitucionalidade 5.537/AL e 5.580/AL. Brasília: MPF, 2016. Disponível em: <https://drive.google.com/file/d/oB4ZHtKQfY--QTGRrTEJvOFlWbTg/view>. Acesso em: 29 set. 2017.

NAGIB, Miguel. Quem Somos. Escola sem partido educação sem doutrinação. [201-]. Disponível em: <http:// escolasempartido.org/quem-somos>. Acesso em: 26 set. 2017.

ORGANIZAÇÃO PARA COOPERAÇÃO E DESENVOLVIMENTO ECONÔMICO. Education at a Glance 2016: OECD Indicators. Paris: OECD Publishing, 2016.

PIOVESAN, Flávia. Direitos humanos e o direito constitucional internacional. 14. ed. Rev. e atual. São Paulo: Saraiva, 2013.

PROFESSORES CONTRA O ESCOLA SEM PARTIDO. Vigiando os projetos de lei. 2017. Disponível em: <https://professorescontraoescolasempartido.wordpress. com/vigiando-os-projetos-de-lei/>. Acesso em: 27 set. 2017.

RESENDE, Leandro. "Escola sem partido" quer fim da “doutrinação de esquerda". 6 set. 2015. O Dia. Disponível em: <http://odia.ig.com.br/noticia/brasil/2015-09-06/ escola-sem-partido-quer-fim-da-doutrinacao-de-esquerda.html>. Acesso em: 29 set. 2017.

SANTOS, Fabiano; SZWAKO, José. Da ruptura à reconstrução democrática no Brasil. Saúde debate, Rio de Janeiro, v. 40, n. esp., p. 114-121, dez. 2016.

SAVIANI, Demerval. O trabalho como princípio educativo frente às novas tecnologias. In: FERRETTI, Celso João et al. (Org.). Novas tecnologias, trabalho e educação: um debate multidisciplinar. Petrópolis: Vozes, 1994. p. 151-166.

SAVIANI, Demerval. O legado educacional do "longo século XX" brasileiro. In: SAVIANI, Demerval et al. O legado educacional do século XX no Brasil. Campinas: Autores Associados, 2004. p. 9-57. (Coleção educação contemporânea).

SAVIANI, Demerval. "Escola sem Partido": o que isso significa?. 2017. Disponível em: <http://www.vermelho. org.br/noticia/301679-1>. Acesso em: 25 set. 2017. 
65 O DISCURSO FALACIOSO DO MOVIMENTO ESCOLA SEM PARTIDO

SILVA, Luís Gustavo Moreira da; FERREIRA, Tarcísio José. O papel da escola e suas demandas sociais. Periódico Científico Projeção e Docência, v. 5, n. 2, p. 6-23, 2014.

UNITED NATION EDUCATIONAL, SCIENTIFIC AND CULTURAL ORGANIZATION. The Global Information Technology Report 2016 - Innovating in the Digital Economy. Genebra: UNESCO, 2016.

YOUNG, Michael. Para que servem as escolas? Educ. Soc., Campinas, v. 28, n. 101, p. 1287-1302, set./dez. 2007.

Recebido em: 30/09/2017

Aprovado em: 30/11/2017 